\title{
Carnitine-induced senescence in glioblastoma cells
}

\author{
SHUICHI YAMADA ${ }^{1}$, RYOSUKE MATSUDA ${ }^{1}$, FUMIHIKO NISHIMURA ${ }^{1}$, ICHIRO NAKAGAWA $^{1}$, \\ YASUSHI MOTOYAMA ${ }^{1}$, YOUNG-SU PARK ${ }^{1}$, MITSUTOSHI NAKAMURA ${ }^{1}$, \\ HIROYUKI NAKASE $^{1}$, YUKITERU OUJI ${ }^{2}$ and MASAHIDE YOSHIKAWA ${ }^{2}$
}

Departments of ${ }^{1}$ Neurosurgery and ${ }^{2}$ Pathogen, Infection and Immunity, Nara Medical University, Kashihara, Nara, Japan

Received February 25, 2012; Accepted April 13, 2012

DOI: $10.3892 / \mathrm{etm} .2012 .556$

\begin{abstract}
Carnitine is essential for lipid metabolism in cells and is known to possess antioxidant properties. Previous reports have suggested that antioxidants are able to induce senescence in glioblastoma cells, consequently, in the present study, we investigated the effect of carnitine on glioblastoma cells. Under conditions of hyponutrition (undernutrition), the proliferation of glioblastoma cells was attenuated and the level of intracellular carnitine was increased. Glioblastoma cell proliferation was also attenuated in cultures that were supplemented with exogenous carnitine, where the induction of senescence was detected by senescence-associated $\beta$-gal (SA- $\beta$-gal) staining. However, there was no evidence of the induction of apoptosis. These effects were not detected when cells were cultured with carnitine plus an inhibitor of p38 mitogen-activated protein kinase (MAPK). It, therefore, appears that carnitine has antioxidant actions in normal cells but induces senescence, which may be regarded as an opposite phenomenon, in glioblastoma cells. Senescence has been reported in cells exposed to temozolomide, which is a standard drug used for the treatment of glioblastoma. Carnitine could, therefore, represent an attractive alternative therapy for glioblastoma.
\end{abstract}

\section{Introduction}

Glioblastoma is the most common malignant type of primary brain tumor found in humans, and the prognosis for patients remains poor despite multimodal therapy including surgery, radiotherapy and chemotherapy $(1,2)$. The median patient survival time following glioblastoma diagnosis is only 12 months owing to characteristic diffuse infiltrations into the surrounding central nervous system tissue $(3,4)$. Therefore, there is an urgent need to develop new approaches to its management.

Correspondence to: Dr Shuichi Yamada, Department of Neurosurgery, Nara Medical University, 840 Shijo-cho, Kashihara, Nara, Japan

E-mail: syamada@naramed-u.ac.jp

Key words: carnitine, glioblastoma, senescence
Cellular senescence leads to the permanent growth arrest of proliferating somatic cells in response to damage and stress from exogenous and endogenous sources (5-7). It is also thought to contribute to a decrease in tissue renewal (that is, the replacement of aged cells), and has recently been recognized as a mechanism of tumor suppression $(5,6,8)$. Several studies have attempted to induce replicative senescence in cancer cell lines using genetic, chemical, or biological treatments (9-11), providing preliminary evidence that senescence has potential as an anticancer therapy.

Carnitine is essential for the $\beta$-oxidation of fatty acids in mitochondria to generate adenosine triphosphate (ATP) in living cells $(12,13)$. Under normal conditions, $70-80 \%$ of human carnitine is obtained through dietary means, although the liver, kidney and brain are capable of biosynthesizing carnitine from lysine and methionine. Carnitine is commonly regarded as an anti-aging agent, since it strongly suppresses the apoptosis of various cell types through the stabilization of mitochondrial membrane permeability (14-16). Furthermore, oxidative damage to mitochondria and cell death in the kidney and intestine, which may be induced by anticancer drugs such as cisplatin, is reported to be inhibited by carnitine (17). It is therefore widely regarded as having a protective effect on cells and tissues. However, few reports to date have documented the effects of carnitine on cancer cell senescence.

Glioblastoma cells in which senescence has been induced by reduced fetal bovine serum (FBS) levels (that is, hyponutrition) show increased amounts of intracellular carnitine. The present study therefore investigated the effects of carnitine on glioblastoma cells in vitro. The addition of exogenous carnitine to the culture attenuated the proliferation of glioblastoma cells and increased the number of senescent cells.

\section{Materials and methods}

Cells. The murine GL261 glioblastoma cell line was provided by A. Natsume of the Department of Neurosurgery at Nagoya University (Nagoya, Japan). The cell culture was maintained in an atmosphere of $5 \% \mathrm{CO}_{2}$ and $95 \%$ humidified air at $37^{\circ} \mathrm{C}$ in Dulbecco's modified Eagle's medium (DMEM; Life Technologies, Grand Island, NY, USA) supplemented with 10\% FBS (Cellgro, Manassas, VA, USA), 2 mM L-glutamine, $100 \mathrm{U} / \mathrm{ml}$ penicillin and $100 \mathrm{mg} / \mathrm{ml}$ streptomycin. Cells were grown to $80-90 \%$ confluence in $75-\mathrm{cm}^{2}$ culture flasks (Corning, Acton, MA, USA) and were subcultured at a ratio of 1:2. 
A

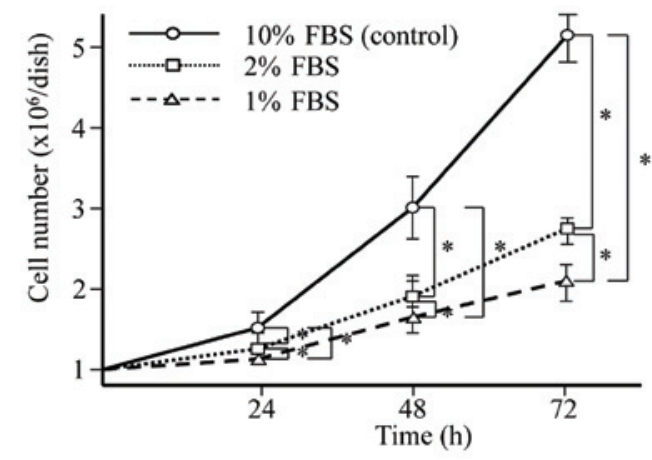

$\mathrm{C}$
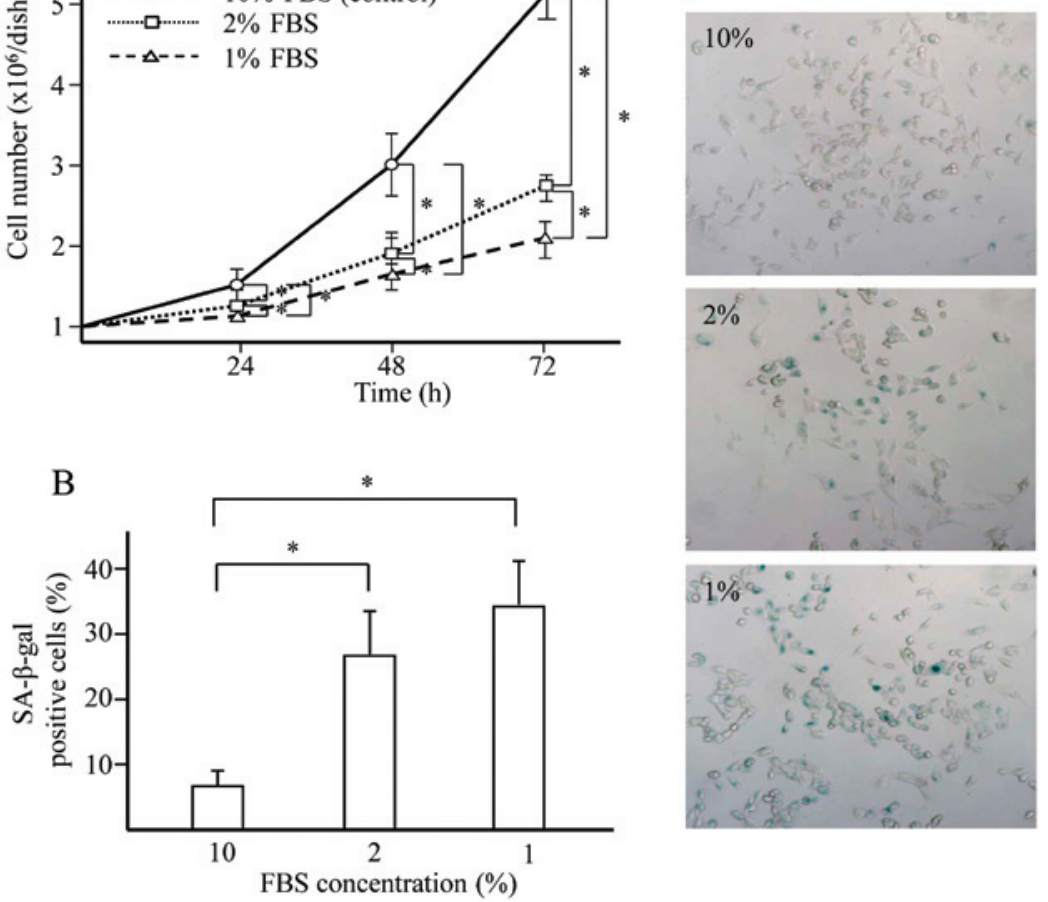

Figure 1. Effect of hyponutrition on cell proliferation and SA- $\beta$-gal-positive senescence. GL261 cells (1x10 $/$ dish) were seeded into 60 -mm dishes and cultured in DMEM supplemented with FBS at concentrations of 1,2 and $10 \%$, and cultivated for 72 h. (A) Number of viable cells over time. (B) Percentage of SA- $\beta$ gal-positive cells according to FBS concentration. "P-value of $<0.05$. (C) Cytochemical staining for SA- $\beta$-gal activity of GL261 cells after cultivation for 72 h. Microphotograph shows positive (blue) cells.

Culture. GL261 cells (approximately $1 \times 10^{6}$ ) were seeded into $60-\mathrm{mm}$ dishes and cultured for $72 \mathrm{~h}$ in DMEM with FBS at concentrations of 1,2 and $10 \%$. Hyponutrition was defined as a culture condition with 1 or $2 \%$ FBS. For some of the experiments, GL261 cells were cultured for $72 \mathrm{~h}$ in DMEM with $10 \%$ FBS in the presence of carnitine (100 or $500 \mu \mathrm{M})$.

Viable cell count. Following washing with phosphate-buffered saline (PBS) to remove dead floating cells, living cells were harvested by trypsinization. Following trypan blue staining, the total number of viable cells was determined by the Vi-XR cell viability counter (Beckman Coulter, Brea, CA, USA) in triplicate.

Intracellular carnitine measurement. Following washing with PBS, GL261 cells were treated with radio-immunoprecipitation assay (RIPA) buffer (Funakoshi, Tokyo, Japan). The cell lysate was collected in a microcentrifuge tube and centrifuged at $20,000 \mathrm{x} \mathrm{g}$ for $5 \mathrm{~min}$. The supernatant was assayed using the enzymatic cycling method (Kainos, Tokyo, Japan), and the carnitine concentration was determined from the amount of accumulated thio-dihydronicotinamide adenine dinucleotide (NADH).

Senescence-associated $\beta$-galactosidase (SA- $\beta$-gal) activity assay. SA- $\beta$-gal activity was measured with a $\beta$-gal staining kit (BioVision, Mountain View, CA, USA) according to the manufacturer's instructions. Briefly, GL261 cells were washed in PBS, fixed for $10 \mathrm{~min}$ at room temperature with $0.5 \mathrm{ml}$ fixative solution, washed and incubated overnight at $37^{\circ} \mathrm{C}$ with the staining solution mix. Blue staining was observed under a microscope, and the absolute number of $\beta$-gal-positive cells in a sample of 200 cells was determined.

SB203580. SB203580, a specific inhibitor of p38 mitogenactivated protein kinase (MAPK), was dissolved in dimethyl sulfoxide (DMSO) and added to the GL261 cell culture at a final concentration of $10 \mu \mathrm{M}$ to determine its effects.

Statistical analysis. Data are expressed as the mean \pm standard deviation (SD) of five independent experiments. Comparisons between two groups with one variable were made using a Tukey-Kramer test for all data, with the exception of cell counts at $48 \mathrm{~h}$ cultured under hyponutrition or with carnitine, which did not show a normal distribution. Instead, Dunnett's test was used to analyze these data.

Data were analyzed using Predictive Analytics SoftWare (PASW) version 18.0.0 (SPSS Japan Inc., IBM, Tokyo, Japan). A P-value less than 0.05 was considered statistically significant.

\section{Results}

Hyponutrition attenuates GL261 cell proliferation and increases GL261 cell senescence (Fig. 1). The proliferation of GL261 cells was attenuated in cells cultured in DMEM supplemented with 1 and 2\% FBS compared with $10 \%$ FBS (the standard concentration) for $72 \mathrm{~h}$. This effect was dose-dependent. Greater numbers of SA- $\beta$-gal-positive senes- 


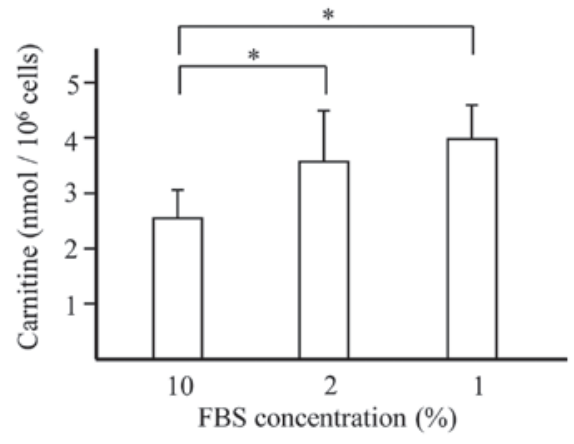

Figure 2. Effect of hyponutrition on intracellular carnitine. GL261 cells were cultured in DMEM with FBS at concentrations of 1,2 and $10 \%$. After cultivation for $72 \mathrm{~h}$, the cells were collected and the amount of intracellular carnitine was assessed. ${ }^{*} \mathrm{P}$-value of $<0.05$.

cent GL261 cells were found in those cultures incubated with 1 and $2 \%$ FBS than in those cultivated with $10 \%$ FBS after $72 \mathrm{~h}$.

Hyponutrition increases intracellular carnitine levels (Fig. 2). Increased levels of carnitine were observed in cells cultured under conditions of hyponutrition compared with cells cultured with the standard concentration of FBS.

Carnitine attenuates cell proliferation and induces cellular senescence (Fig. 3). Increased intracellular carnitine levels were detected in the cultured cells that demonstrated hyponutritioninduced senescence. We therefore added exogenous carnitine to the culture and examined the effects on cell proliferation and senescence. Proliferation was attenuated by carnitine in a dose-dependent manner, while increased numbers of SA- $\beta$ gal-positive cells were observed in the culture supplemented with exogenous carnitine.

SB203580 inhibits the carnitine-induced attenuation of cell proliferation (Fig. 4A). The addition of the specific p38 MAPK inhibitor SB203580 reversed the inhibition of GL261 cell proliferation induced by carnitine. The carnitine-induced attenuation of GL261 cell proliferation therefore appeared to be mediated by the p38 MAPK signaling pathway.

Role of apoptosis in hyponutrition-induced GL261 cell senescence (Fig. 4B). Flow cytometry with Annexin V conjugated to fluorescein (Annexin V-FITC)/propidium iodide (PI) double staining was used to investigate whether apoptosis was involved in the attenuation of proliferation by hyponutrition. No morphological changes were observed under transmission electron microscopy and the number of apoptotic cells did not increase in 1 or $2 \%$ FBS cultures compared with the $10 \%$ culture, suggesting that apoptosis did not play a role in the hyponutrition-induced senescence.

\section{Discussion}

Carnitine is an essential substance for the $\beta$-oxidation of fatty acids in mitochondria and is recognized as an antiaging nutrient $(12,18)$. Several reports have shown that it

A

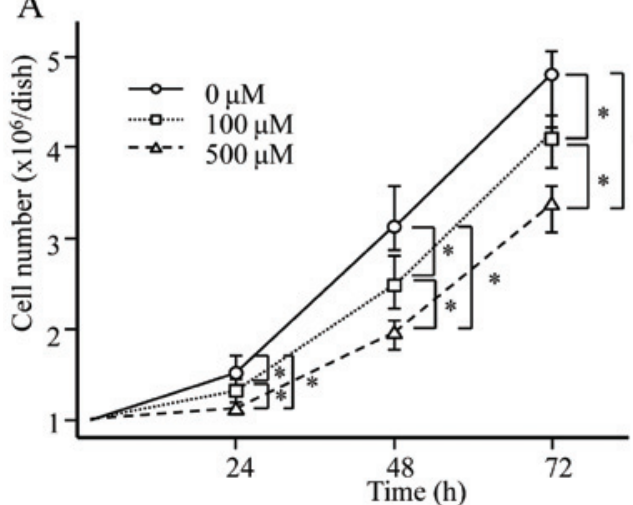

$\mathrm{C}$
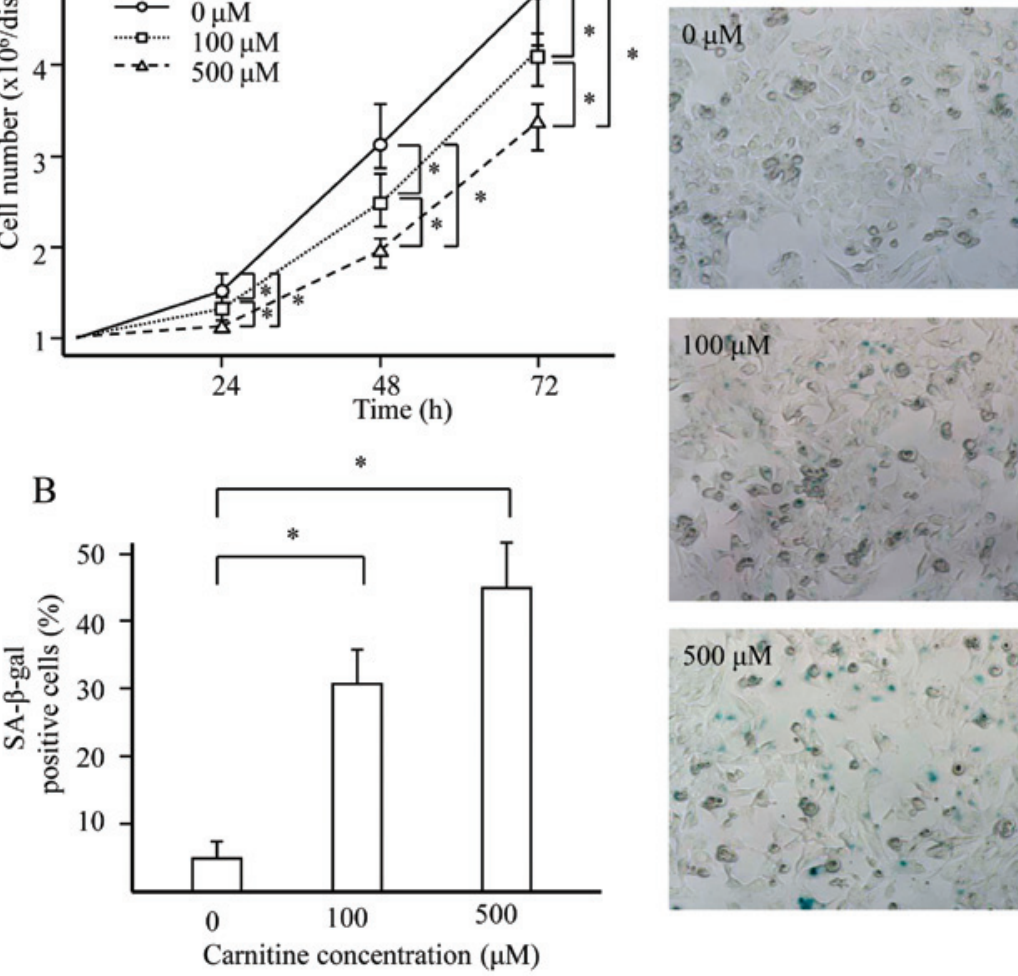

Figure 3. Effect of carnitine on cell proliferation and senescence. GL261 cells were cultured in the presence of carnitine in DMEM with $10 \%$ FBS for $72 \mathrm{~h}$. (A) Viable cells. (B) Cytochemical staining for SA- $\beta$-gal activity of GL261 cells. Microphotograph shows positive (blue) cells. *P-value of <0.05. (C) SA- $\beta$ gal-positive cells. 
A

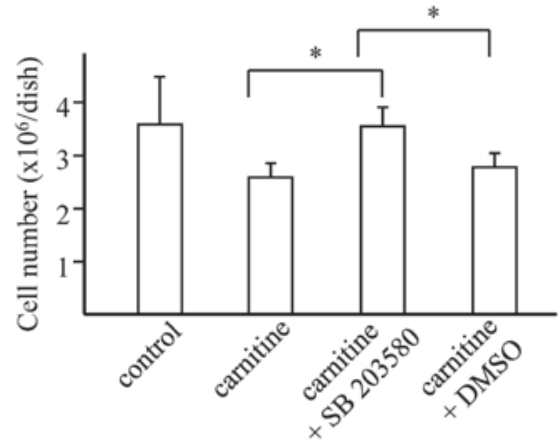

B $10 \%$ FBS (control)

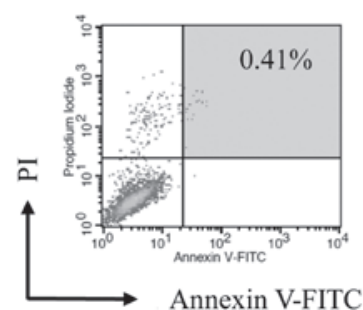

$2 \%$ FBS

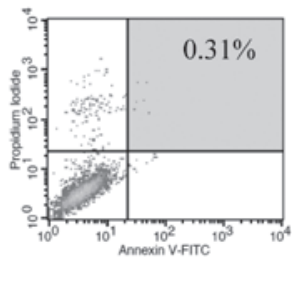

$1 \%$ FBS

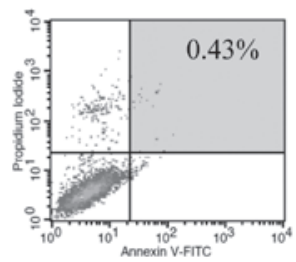

Figure 4. Effect of SB203580 and the result of flow cytometry for GL261 cells cultured under hyponutrition. (A) Effect of SB203580 on the proliferation of GL261 cells treated with carnitine. "P-value of $<0.05$. (B) Number of Annexin V-FITC/PI double-positive cells among the GL261 cells cultured in DMEM supplemented with 1,2 and 10\% FBS.

acts protectively in cells and tissues against various stresses and damage, including the side effects of anticancer chemotherapy (14-17,19). However, few studies have documented the carnitine-induced changes to cancer cells. The present study revealed, for the first time, that carnitine induces senescence in glioblastoma cells. The addition of exogenous carnitine to the culture media attenuated cell proliferation and increased the number of SA- $\beta$-gal-positive senescent cells, suggesting that carnitine promotes cellular senescence. Carnitine shows antioxidant activity in normal cells, which suggests that it plays a crucial role in the prevention of aging. However, it induces senescence in glioblastoma cells, thus it appears to have opposing effects in different target cells.

The attenuation of proliferation and the increase in SA- $\beta$ gal-positive cells induced by exogenous carnitine have been confirmed in the U87MG glioblastoma cell line (Yamada et al, unpublished data). The absence of an increase in apoptosis among glioblastoma cells cultured with carnitine also supports the theory that carnitine induces senescence. The suppression of proliferation by a recognized inhibitor of p38 MAPK, which is part of the common senescence-signaling pathway $(20,21)$, further indicates that carnitine induces senescence in glioblastoma cells.

Treatment-induced senescence (TIS) is of interest in conventional anticancer therapy. Although initially identified in tumors following radiation or genotoxic chemotherapy (9-11), TIS might also be induced at lower drug doses, in contrast to the higher doses at which DNA damage and apoptotic responses are elicited. Temozolomide is widely used for the treatment of glioblastoma $(22,23)$, and has been reported to induce senescence without apoptosis in melanoma cells (24). The present study demonstrated that carnitine induced senescence in glioma cells. Considering its beneficial effects on aging and the side effects of anticancer drugs, the use of carnitine in combination with chemotherapy could represent an attractive alternative therapy for glioblastoma, which currently lacks an effective treatment.

In addition to carnitine, the polyphenolic phytoalexin resveratrol, found in grapes and other foods such as nuts, has well-known effects on aging, metabolic disorders, and inflammation $(25,26)$. Indeed, it was recently reported to induce cellular senescence in carcinoma cells, including glioblastoma cells (27). Notably, its activity increased when it was administered in combination with the senescence-inducing nutrient quercetin. Although it is not yet known how resveratrol performs in association with carnitine, combining food nutrients with chemotherapy and radiation therapy might further improve outcomes in the treatment of glioblastoma.

\section{References}

1. Behin A, Hoang-Xuan K, Carpentier AF and Delattre JY: Primary brain tumours in adults. Lancet 361: 323-331, 2003.

2. Preusser M, de Ribaupierre S, Wohrer A, et al: Current concepts and management of glioblastoma. Ann Neurol 70: 9-21, 2011.

3. Lacroix M, Abi-Said D, Fourney DR, et al: A multivariate analysis of 416 patients with glioblastoma multiforme: prognosis, extent of resection, and survival. J Neurosurg 95: 190-198, 2001.

4. Lefranc F, Sadeghi N, Camby I, Metens T, Dewitte O and Kiss R: Present and potential future issues in glioblastoma treatment. Expert Rev Anticancer Ther 6: 719-732, 2006.

5. Ewald JA, Desotelle JA, Wilding G and Jarrard DF: Therapyinduced senescence in cancer. J Natl Cancer Inst 102: 1536-1546, 2010.

6. Kuilman T, Michaloglou C, Mooi WJ and Peeper DS: The essence of senescence. Genes Dev 24: 2463-2479, 2010.

7. Rodier F and Campisi J: Four faces of cellular senescence. J Cell Biol 192: 547-556, 2011.

8. Campisi J: Senescent cells, tumor suppression, and organismal aging: good citizens, bad neighbors. Cell 120: 513-522, 2005.

9. Gewirtz DA, Holt SE and Elmore LW: Accelerated senescence: an emerging role in tumor cell response to chemotherapy and radiation. Biochem Pharmacol 76: 947-957, 2008. 
10. Roberson RS, Kussick SJ, Vallieres E, Chen SY and Wu DY: Escape from therapy-induced accelerated cellular senescence in p53-null lung cancer cells and in human lung cancers. Cancer Res 65: 2795-2803, 2005.

11. Te Poele RH, Okorokov AL, Jardine L, Cummings J and Joel SP: DNA damage is able to induce senescence in tumor cells in vitro and in vivo. Cancer Res 62: 1876-1883, 2002.

12. Flanagan JL, Simmons PA, Vehige J, Willcox MD and Garrett Q: Role of carnitine in disease. Nutr Metab (Lond) 7: 30, 2010.

13. Yano H, Oyanagi E, Kato Y, Samejima Y, Sasaki J and Utsumi K: L-carnitine is essential to beta-oxidation of quarried fatty acid from mitochondrial membrane by PLA(2). Mol Cel Biochem 342: 95-100, 2010.

14. Wang C, Sadovova N, Ali HK, et al: L-carnitine protects neurons from 1-methyl-4-phenylpyridinium-induced neuronal apoptosis in rat forebrain culture. Neuroscience 144: 46-55, 2007.

15. Revoltella RP, Dal Canto B, Caracciolo L and D'Urso CM: L-carnitine and some of its analogs delay the onset of apoptotic cell death initiated in murine $\mathrm{C} 2.8$ hepatocytic cells after hepatocyte growth factor deprivation. Biochim Biophys Acta 1224 333-341, 1994

16. Sparagna GC, Hickson-Bick DL, Buja LM and McMillin JB: A metabolic role for mitochondria in palmitate-induced cardiac myocyte apoptosis. Am J Physiol Heart Circ Physiol 279: H2124-H2132, 2000.

17. Chang B, Nishikawa M, Sato E, Utsumi K and Inoue $M$ L-Carnitine inhibits cisplatin-induced injury of the kidney and small intestine. Arch Biochem Biophys 405: 55-64, 2002.

18. Calabrese V, Cornelius C, Stella AM and Calabrese EJ: Cellular stress responses, mitostress and carnitine insufficiencies as critical determinants in aging and neurodegenerative disorders: role of hormesis and vitagenes. Neurochem Res 35: 1880-1915, 2010 .
19. Rauchova H, Koudelova J, Drahota Z and Mourek J: Hypoxiainduced lipid peroxidation in rat brain and protective effect of carnitine and phosphocreatine. Neurochem Res 27: 899-904, 2002.

20. Coulthard LR, White DE, Jones DL, McDermott MF and Burchill SA: p38(MAPK): stress responses from molecular mechanisms to therapeutics. Trends Mol Med 15: 369-379, 2009.

21. Debacq-Chainiaux F, Boilan E, Dedessus Le Moutier J, Weemaels G and Toussaint O: p38 (MAPK) in the senescence of human and murine fibroblasts. Adv Exp Med Biol 694: 126-137, 2010.

22. Malkoun N, Chargari C, Forest F, et al: Prolonged temozolomide for treatment of glioblastoma: preliminary clinical results and prognostic value of p53 overexpression. J Neurooncol 106: 127-133, 2012.

23. Stupp R, Mason WP, van den Bent MJ, et al: Radiotherapy plus concomitant and adjuvant temozolomide for glioblastoma. N Engl J Med 352: 987-996, 2005.

24. Mhaidat NM, Zhang XD, Allen J, Avery-Kiejda KA, Scott RJ and Hersey P: Temozolomide induces senescence but not apoptosis in human melanoma cells. Br J Cancer 97: 1225-1233, 2007.

25. De la Lastra CA and Villegas I: Resveratrol as an antiinflammatory and anti-aging agent: mechanisms and clinical implications. Mol Nutr Food Res 49: 405-430, 2005.

26. Um JH, Park SJ, Kang H, et al: AMP-activated protein kinasedeficient mice are resistant to the metabolic effects of resveratrol. Diabetes 59: 554-563, 2010.

27. Zamin LL, Filippi-Chiela EC, Dillenburg-Pilla P, Horn F, Salbego C and Lenz G: Resveratrol and quercetin cooperate to induce senescence-like growth arrest in C6 rat glioma cells. Cancer Sci 100: 1655-1662, 2009. 